\title{
LEXICON
}

Volume 7, Number 2 (October 2020)

Pages 182-189

https://jurnal.ugm.ac.id/lexicon

https://doi.org/10.22146/lexicon.v7i2.66567

\section{"Octonauts": Blending in the Names of BBC UK Children's Programs}

\author{
Amanda Amalia Noor Arifah, Rio Rini Diah Moehkardi* \\ English Department, Universitas Gadjah Mada, Indonesia \\ *Corresponding Author: riomoehkardi@ugm.ac.id
}

\begin{abstract}
This research investigates the formation process of the blends in the names of the BBC UK children's programs and their semantic changes. The methods used in this research are descriptive qualitative, and quantitative. To analyze the formation and classification of the blends, the writer used the theory proposed by Mattiello (2013). The results show that morphotactically, the blends are categorized into total and partial blends. Morphonologically, the blends are classified into overlapping and nonoverlapping blends. Morphosemantically, the attributive blends are more frequently used than the coordinative blends. Furthermore, there are some semantic changes found in the attributive blends.
\end{abstract}

Keywords: blending, BBC UK children's program, formation process, semantic change.

\section{INTRODUCTION}

People try to sell their products in different ways, one of which is by using unique brand names. They mostly create new words to create brand names. Forming new words is usually associated with wordformation processes.

There are various processes to form a new word with new meanings and purposes. One of them is called blending. Since "blending has become a highly frequent word formation process" (Mattiello, $2013 \mathrm{p}$. 111) that is used in the modern era, people use blends to create names for their products such as Chitato (chips+potato), Hydrococo (hydro+coconut), and Wine'tastic (wine+fantastic) (Moehkardi, 2016).

Moreover, blends are also frequently used in the entertainment industry. The blend words are usually used as the characters' names in movies, the setting of places, the titles, and the terms related to the movies. There are several examples of terms that used blends in movies such as Incrediboy (incredible+boy), spooktackles (spooky + spectacles), aristocats (aristocracy+cat), and freshalicious (fresh+delicious) (Gorčević, Dazdarević \& Zoranić, 2016).

The blending process is also implemented in the names of BBC UK children's programs. The BBC (The British Broadcasting Corporation) is a public service broadcaster and the oldest national broadcasting organization globally. BBC UK has many entertainment programs for different age groups, including children. There are many uses of blend words in the BBC children's programs, especially in the United Kingdom. We analyze the names of the programs in BBC using a morphological approach to explain the word-formation process. Some examples of the blends used in the names of the 
programs are: Octonauts (octopus+astronaut), Championsheep (champion-ship+sheep), Alphablocks (alphabet+blocks), Christ-mastacular (Christmas+spectacular), Gruffalo (gruff +buffalo).

BBC attempts to attract children by creating unique program names through blending. The uniqueness of the name encourages children to watch the program. We are interested in conducting further research on blending and its meaning since there are many unique blends used in the names of the programs. The meaning of the word might also change due to the blending process because the root words are modified. Furthermore, we also analyze the semantic change of the attributive blends based on their components of meaning. We hope that this research could encourage more producers to name their entertainment program using unique titles through blending.

\section{LITERATURE REVIEW}

There have been some studies focusing on blending. Hosseinzadeh (2014) investigated the blending formation process using Yule's theory. The results show that most of the data are formed by clipping and overlapping. Another study by Setyowati (2015) examined the blending strategies used in 25 names of brands using Plag's theories. The results show that $\mathrm{AD}$ form is higher than AC. Similar to Ratna Setyowati's research, Maulana (2016) applied the theory of Plag, but he identified each pattern and measured the size of the syllable. The most common pattern is syllable + syllable.

Another research conducted by Sangshita (2017) focuses on blending in advertisement for event. She found 50 names of events and classified them into five categories based on Hosseinzadeh's classification.

The previous studies focused on the process of blends and classified them into some categories. Also, most of them apply Plag's theory. Meanwhile, this research focuses on names of children's programs and uses Mattielo's theory to analyze the formation processes of the blends found in the names of the BBC UK children's programs.

\section{THEORETICAL FRAMEWORK}

Blending is combining two parts of at least two words (Yule, 2010). Blend words are mostly built of two or more source words, but the base words cut with a massive loss of phonetic (or orthographic) material (Plag, 2003). Blend words have often been described as a rather irregular phenomenon where the rule is not transparent.

Furthermore, Mattiello (2013), in her book, defines blend words as newly formed words that are created by "merging parts of existing words, as in beaulicious (beautiful + delicious), or one complete word and part of another as in chatire (chat + satire)" (p. 111). Mattiello emphasized that blending is usually used to denote a word formation process which combines two source lexemes, at least one of which may be shortened in the combination, sometimes with a graphic and/or phonological overlap (p. 112).

Sometimes, blends are mistaken with compounds. Lehrer said that "blends are underlying compounds which are composed of one word and part of another, or parts of two (occasionally three) other words" (as cited in Mattiello, 2013 p. 113). In line with that, Kemmer (as cited in Mattiello, 2013, p. 114) stated that blends are different from compounds because "they combine parts of lexical source words, rather than the whole source words". Mattiello (2013, p. 5) concluded that blends are similar to compounds in terms of their word components that are up to 2-3 words. However, unlike compounds, blends are extra-grammatical. Blends undergo shortening and recombining process, and thus, have a higher degree of creativity than compounds.

Blends are formed by shortening the parts of the source words. The parts that are shortened irregularly in the source word of blending are called splinters. The word splinter is firstly used by Adams (as cited in Danks, 2003) to distinguish it from source words. Splinter is different from morpheme and clipping because it does not function as a full word. Bauer (1983,) define splinter as "originally (mostly) non-morphemic portions of a word that have been split off and used in the formation of new words with a specific new meaning" (p. 525). Besides, splinters 
cannot stand alone as a word, although it is a clipping (Lehrer, 2003). However, when splinter becomes highly frequently used and famous, it can stand alone as a word (Bauer, 1983).

Soudek (as cited in Moehkardi, 2019) distinguishes splinters into two: initial splinter and final splinter, based on the elements of the blend; the first part for the former, and the second element of the blend for the latter. Moreover, Danks (2003) agrees that splinters are used to describe "bit" from the source word truncated in the blends. However, she also stated that blending may not only use splinter, but also two overlapping words such as Japanimation (Japan + animation).

\section{METHODS}

We use library research as the method of this research. The primary sources of the data were the names of the BBC UK children's programs. The names were obtained from the titles of the programs. All of the data were English words. The data were collected by taking notes of the program's titles.

First, we visited www.bbc.co.uk and searched the list of children's programs on the BBC website. Then, we listed the blends found in the names of the programs. The data were obtained through all BBC programs, including the radio program, documentary program, and others.

Besides collecting the data, we also read the theories about blending. After that, we took note of the theories, concepts, and definitions to analyze the data. We also observed the context (the poster and the description of the programs) to get the most accurate data.

We analyzed the process of blending based on Mattiello's theory (2013). We grouped the data into morphotactical, morphonological or graphic, and morphosemantic blends. Furthermore, we analyzed the components of meaning of attributive blends using Merriam Webster Dictionary. We also analyzed the semantic change in the attributive blends.

\section{RESULTS AND DISCUSSION}

Altogether 35 blends were found in the names of BBC UK children's programs out of 1,867 children's programs names. These blends are newly created English words and cannot be found in any dictionary. There are six total blends and 29 partial blends found in morphotactic category. There are 13 overlapped blends and 22 non-overlapped blends found in morphonological and graphic categories. Morphosemantically, there are 30 attributive blends, and 5 coordinate blends found.

The analysis of the data is presented based on Mattiello's classification. Besides, phonetic transcription is also presented based on the International Phonetic Alphabet. The semantic change of the attributive blends is also presented along with its components of meaning. The data presented in the table are in random order.

\section{Morphotactical Blends}

Morphotactically, the blends are divided into total blends and partial blends. This type shows the part of the source words that are used in forming the blends.

\section{Total Blends}

In this category, all source words are shortened to be splinters and grouped into four sub-categories.

a. The beginning splinter of the first source word followed by the end of second source word.

There are three blends found in this subcategory. The structure of the blends in this subcategory is the initial splinter combined with the final splinter. There are various numbers of letters that are taken from the source words. For instance, the word dinosapien combines two syllables of dino in dinosaur, and three syllables of sapien in Homosapien. Iconicles combines two syllables of icon in iconic and two syllables of icle in particle. Last, octonauts combines two syllables of octo in octopus and one syllable of naut in astronaut. The affix "s" in the iconicles and octonauts shows the 
various numbers of iconicle and octonaut shown in the program. As a result, there is no specific rule in this sub-category because the blends are formed unpredictably. However, the pattern of the data can be seen through its structure.

b. The beginning splinter of the first source word followed by the beginning of second word.

There are three blends found in this subcategory and all of them are nouns. The blends are formed of two fore clippings. The word cineminis is pronounced as in the original words. It is pronounced as cineminis, which is the same as cine in cinema and mini in minimalist. Meanwhile, the pronunciation of the word numtums is different from its original words. It is pronounced as /nümtüms/, the num is pronounced differently from num in number, and tum is different as in to me.

\section{Partial Blends}

In this category, only one source word is shortened to a splinter. There are three sub-categories for this. The structure of the blends in this category is full part of word of one source word combined with splinters of another source word.

a. The first source word is not shortened, and the other is shortened to a splinter.

There are 14 blends found in this sub-category. The blends take all parts of the first source word and add either the initial splinter or final splinter of the second source word. There are 11 blends formed by combining the first full source word with the final splinter as in appsolute. The word appsolute combines app, which is a clip from application, and absolute. This formation process is quite common in forming blends by using clip words as the source words.

Three blends are formed by combining the first full source word with the initial splinter as in superted. The word superted is formed from super and Teddy.

Another structure can be seen through the word zombieville. The word village is clipped into vill, and it is written as ville. The use of the morpheme ville, a French morpheme meaning village, is common in UK. This structure is also acceptable in forming blends since blends are formed irregularly. The more unique the blend, the more attractive it is.

b. The first source word is shortened to a splinter, and the other is not.

There are 14 blends found in this sub-category. All of them are initial splinters followed by full word. Sometimes, it only takes one letter, such as $d$ from designer in the dengineer and $s$ from science in the sparticle. It could also take the whole word, such as champion in championsheep.

Another possibility of blending is also found in Teletubbies. The word tubby changed into tubbies to make it more ear-catching. There is no obvious explanation about this since the blends are formed freely. However, this structure is still acceptable in blending.

c. The first source word is intercalated with a splinter.

Only one blend hartbeat is found in this subcategory. The second source word, art, is inserted without a cut in the initial splinter ( $h \_$beat). The word that is intercalated shares similar sound with the replaced splinter. The phones /ärt/ is rather similar with the sound /härt/ in heartbeat.

\section{Morphonological or Graphic Blends}

This type of blends is classified into two based on the similarity of the sound and/or graph in both source words. They are overlapping blends and nonoverlapping blends.

\section{Overlapping Blends}

Blends belong to this type if the phones and/or graph of both source words are overlapping. There are two sub-categories of this type: the blends that are overlapped without shortening and the blends that are overlapped with shortening.

a. Blends without shortening

There are three blends found in this subcategory. Both source words of the blends do not lose anything. The blends have the same spelling and pronunciation. For instance, in the cinemaniac the 
syllable 'ma' in cinema and maniac is pronounced as /mä/.

In another case, there is a letter $s$ in carstoon. This letter is inserted to make it sound more like a blend. If the blend is written as cartoon, people might have less curiosity since it might have the literal meaning as an animated movie. However, if it is written as carstoon, it attracts people's attention to discover its meaning. This is also acceptable reason of creating blends.

\section{b. Blends with shortening}

There are six blends found in this sub-category. One of the source words is reduced into a splinter. Three of the six blends use a pattern in which only one letter overlaps: aphablocks (alphabet + blocks), dengineer (designer + engineer), and internot (internet + not). Meanwhile, there is no pattern in the number of shortened letters. There are two letters shortened in aphablocks, gruffalo, internot, six letters shortened in dengineer, one letter shortened in gnomeo, and three letters shortened in iconicles.

The structure of the initial splinter overlapping with the full word has the same number as full word overlapping with the final splinter. The first structure can be seen in alphablocks, dengineer, and internot. Meanwhile, the second structure can be seen in data gnomeo, gruffalo, and iconicles .

\section{Phonological overlap}

This type of blends can be identified from their spelling: appsolute, hartbeat, championsheep and barkstage. The pronunciation of the source words in appsolute and hartbeat are completely similar: apps +

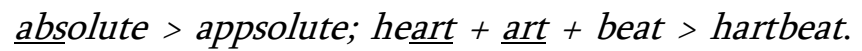
Meanwhile, the pronunciation of source words in championsheep and barkstage are rather similar: championship + sheep > championsheep, where ship and sheep are prnounced rather similar, so are bark and back in bark + backstage > barkstage. However, this structure is still acceptable since it is articulated in the same way.

\section{Non-Overlapping Blends}

There are 22 blends found. The blends do not share letters or sounds and do not have similarities in graphs and phones, for example, zoo + metropolis $>$ zoopolis. However, the word smarteenies is unique. It is formed of smart and teenager'. The word smart is an overlapped blend of smart+ art. This shows that a blend may have a multi-level process. Nevertheless, it is still categorized in this sub-category since the main focus of this blend is on the word teenager.

\section{Morphosemantic Blends}

Morphosemantically, the blends are divided into attributive blends and coordinate blends. The place of the heads and modifier distinguishes them one another.

\section{Attributive blends}

The blends in this type have a semantic head. The head could be outside or inside the blends. The blends that have inside heads belong to endocentric blends. The endocentric blends are divided into right headed and left headed blends.

In this section, it is also important to analyze the meaning of the blends since they are modified words. This modification may create a different meaning. Therefore, we analyze the semantic change between the attributive blends and their source words.

There are 30 blends found in this type which is dominated by the combination of nouns. There are 17 left headed blends, 9 right headed blends, and 4 exocentric blends.

\section{Semantic Change}

We also categorized the attributive blends into four different categories. Those are animals, art, science, and others.

The result shows that $29 \%$ of the blends found in the attributive type belong to science words, $24 \%$ 
belong to animals, $18 \%$ belong to art, and 29\% cannot be classified into those categories. The words that belong to science words are, appsolute, internot, Frankenfacts, Frankenweenie, numtum, teletubbies, gastronuts, moondial, zombieville, and iconicle. There is no science word in those words. However, each word in those blends represents the elements of science. For instance, the words app, internet, Frankenstein, number, television, moon, and zombie are usually related to science. The words zombie and Frankenstein are usually related to the dead body manipulated to be alive again with the power of science. Meanwhile, the words gastronuts and iconicle show science activity on its program. Therefore, those words are categorized into science based on the context.

The blends related to animal words are dinopaws, dinosapien, octonauts, championsheep, Frankensheep, gruffalo, animaltastic, and petsaurus. The words dinosaur, octopus, sheep, and buffalo are names of animals except for the words animal and pet. However, these words can be considered animal words since the programs talk about animals.

Moreover, the words cinemaniac, cineminis, hartbeat, smart, smarteenines, and carstoon belong to art words. There is an 'art' word in the hartbeat, smart, and smarteenies. Moreover, the words cinemaniacs, cineminis, and carstoon still belong to art because the programs are about art.

\section{Coordinate Blends}

In this sub-category, there are five blends found. All of the blends are nouns. The blends have two semantic heads. Further, they have the same semantic classes that equally contribute to the meaning. The blends found are all endocentric. Since the blends could not be found in any dictionary, it is necessary to know the context to understand the meaning of each blend. We analyze the poster and picture of the programs to understand their context.

The word dinosapien comes from dinosaur and Homo sapiens. Homo sapiens is the species of human being that exist today (Merriam Webster Dictionary, 2019). However, the word Homo sapiens can also be defined as the first human being that experienced evolution. Dinosapien has features of both dinosaur and Homo sapiens. Both source words equally contribute to creating the blend.
The blend alphablocks is formed from alphabet and blocks. It means that the alphabetical characters are written in each block. Both alphabet and block are equivalent in creating the blend.

Such equivalence also happens to the word Gnomeo. It is a gnome-Romeo. The original name of this program is Gnomeo and Juliet. It shows that Gnomeo would be a creature of a half dwarf-shape and a half Romeo that falls in love with Juliet. Both gnome and Romeo have the same contribution in the blend.

This also happens to the blends dengineers and sparticle. Denginer is formed from designer and engineer whereas sparticle is formed from science and particle. Although the blends only take one letter of the first source word, both source words contribute to creating meaning.

\section{CONCLUSION}

There are 35 blends found in the names of BBC UK children's programs. All of the data are analyzed using Elisa Mattiello's theory. The data are classified into three: morphotactic blends, morphonology and graphic blends, and morphosemantic blends. Besides, the attributive blends are also analyzed through its semantic change based on its meaning components.

Morphotactically, blends can be distinguished based on which part of source word used in the blend. It can be that both source words are shortened into splinter or only one source word reduced to splinter. However, at least one of the source words is reduced to splinter. The result shows six total blends in which three data of combination initial splinter followed by final splinter, and three data of the combination of initial splinter followed by initial splinter. Further, the most frequently used structure is the partial blends ( 29 data). Fourteen data belong to the type of blends that full word followed by splinter, 14 data of splinter followed by full word, and one intercalated blends.

Morphonologically and graphically, the blends are categorized based on the similarity of sound and graph of the source words. The most frequently used type is non-overlapping blends (22 data). There are only 13 blends found in the overlapping blends. 
Three data belong to overlapped blends with no shortening, six data belong to overlapped blends with shortening, and four data belong to phonological overlapped.

Morphosemantically, the data analyzed based on its semantic relationship. The most dominated formation is the attributive blends with 30 data. It included 17 left-headed blends, 14 left-headed blends, and four exocentric blends. Also, five data belong to coordinative blends. All of the coordinative blends are endocentric blends.

Moreover, in the attributive blends, the words changed semantically from their source words. The type of semantic change found in the attributive blends is the shift type. The meaning of the blends is totally different from its original meaning in the source words. It happens because the source words are modified into blends. When a word is modified, the meaning of the original word will change. At least, there is a change in the connotation of the word.

In conclusion, the characteristics of blends can be seen through their structure. The blends can be formed by shortening both source words into splinter or only one of the source words The length of the shortened parts into splinters is random. Moreover, the result shows that there is no data that is not categorized in the Mattiello's classification. Last, the blends are modified words. Once a word is modified, the meaning changed. In this case, because the blends are creatively formed, ear-catching, and interesting in their semantic change, people get interested in putting it on the advertisement and entertainment.

\section{REFERENCES}

Bauer, L. (1983). English Word Formation.

Cambridge University Press.

Danks, D. (2003). Separating blends: A formal investigation of the blending process in English and its relationship to associated word formation processes. (Unpublished master's thesis). The University of Liverpool, Liverpool, U. K.
Gorcevic, A., Dazdarević, S., \& Zoranić, A. L. (2016). Investigation of animated film blends in English discourse. Linguistics and Literature, 14(1), 25-40.

Hosseinzadeh, N. M. (2014). New blends in English language". International Journal of English Language and Linguistics Research, 2(2), 1516.

Lehrer, A. (2003). Understanding trendy neologism. Rivista di Linguistica, 15(2), 371-384.

Mattiello, E. (2013). Extra-grammatical morphology in English: Abbreviations, blends, reduplicatives, and related Phenomena. De Gruyter Mouton.

Mattiello, E. (2017). Paradigmatic morphology splinters, combining forms, and secreted affixes. SKASE Journal of Theoretical Linguistics, 15(1), 1-22.

Maulana, B. (2016). Blending strategies used in branding mobile application: Prosodic morphology analysis. (Unpublished undergraduate thesis). Universitas Gadjah Mada, Yogyakarta, Indonesia.

Merriam-Webster Online Dictionary. (n.d.). Retrieved from https://www.merriamwebster.com/dictionary.

Moehkardi, R. R. D. (2016). Patterns and meanings of English word through word formation processes of acronyms, clipping, compound and blending found in Internet-based media. Humaniora, 28(3), 324-338.

Moehkardi, R. R. D. (2019). English blends in Indonesian context: Their formation processes and meanings. Humaniora, 3(1), 21-32.

Plag, I. (2003). Word-formation in English. Cambridge University Press.

Programmes. (n.d.). Retrieved from BBC,www.bbc.co.uk/programmes/genres/chil drens/entertainmentandcomedy/all.

Sangshita, S. B.. (2018). Blending in advertisements for events: A morphological study. Lexicon, 5(2), 194-199. 
Amanda A. N. Arifah \& Rio R. D. Moehkardi / Blending | 189

Setyowati, R. (2015). Prosodic Morphological

Analysis on Blends Used As Brand of Snack and Baverages. Lexicon, 4(2), 81-89.
Yule, G. (2010). The Study of Language (4th Ed.) Cambridge University Press. 